Kairos. Journal of Philosophy \& Science 22, 2019

Center for the Philosophy of Sciences of Lisbon University

\title{
The Ontological Concept of Disease and the Clinical Empiricism of Thomas Sydenham
}

\author{
Ruy J. Henríquez Garrido \\ Facultad de Filosofía \\ Universidad Complutense de Madrid \\ ruyhenriquez@filos.ucm.es
}

DOI 10.2478/kjps-2019-0013

\begin{abstract}
The clinical empiricism of Thomas Sydenham (1624-1689) and his definition of especie morbosae represented a substantial turn in the medicine of his time. This turn supposed the shift towards an ontological conception of diseases, from a qualitative to quantitative interpretation. Sydenham's clinical proposal had a great influence on empiricism philosophical thinking, particularly in John Locke and his delimitation of knowledge. The dialogue between medicine and philosophy, set out by Sydenham-Locke, reactivates the problem of the clinical and theoretical foundations of medical thought, as well as the limits of scientific knowledge. Similar to problem exposed in the Hippocratic treatise On ancient medicine, seventeenth-century medicine seeks its epistemological foundations and the solution to its difficulties in clinical experience, probability and analogy. The aim of this work is to show the Sydenham's contribution to one of the great controversies between medicine and philosophy.
\end{abstract}

Keywords: Sydenham, Locke, Hippocrates, On ancient medicine, especie morbosae, clinical empiricism, ontological concept of disease, analogy, probability.

\section{Introduction}

The clinical empiricism of Thomas Sydenham and his definition of disease like especie morbosae, implied the change from a fundamentally 
physiological research tradition, to an ontological conception of diseases. This transition also marked the passage from a qualitative notion to a quantitative conception that would initiate a transformation of medical nosography.

Sydenham, inspired by the methodology of the botanist John Ray and the philosophical principles of Francis Bacon, opens the way to a definition of disease as an objective, autonomous and orderly fact, producing an empiricist turn in Baroque Medicine. The supports of his medical reform were the creation of a "natural history of diseases" and the development of a "general method of cure", regular and accurate. Sydenham's proposal represented the decisive step towards a quantitative consideration of the medical object.

Locke's empiricist conception found in the Sydenham clinic a source of inspiration for his definition of the empirical epistemological method and his general formulation of knowledge. Of the numerous coincidences between Sydenham-Locke, I will highlight two that I consider essential: the rejection of knowledge based on hypotheses not empirically tested and the use of "historical and simple method".

With the emergence of Sydenham and Locke, the old discussion about medical clinic and theoretical assumptions, which took place between medicine and philosophy, is revived. The cyclical nature of this controversy seems to find again the solution to the difficulties generated by empiricism in the analogy and probability.

In this paper, I will initially present some important consequences of the definition of disease as especie morbosae. Next, I will review the coincidences of Sydenham's position with the hypocritical theses presented in On ancient medicine (VM). ' Finally, I will review the importance of the Sydenham clinic in empiricist philosophy and the solutions that Locke proposes to the difficulties of empiricism.

While it is true that the shift towards an ontological idea of diseases implied a significant change in the way of addressing and interpreting

$1 \quad$ For space limitations and coherence, I will limit myself to finding the coincidences and differences between Sydenham's proposal and Hippocratic medicine, leaving Hellenistic medicine aside. The controversy between empiricists and rationalists that took place in this period, due to its length and complexity, deserves one separate work. 
health and disease, our main interest is to investigate the epistemological background of the issue, rather than the purely nosological definitions.

\section{The Disease Like a Especie Morbosae}

In the preface to his Observations medicae cisca morborum acutorum historiam et curationem (1676), ${ }^{2}$ Sydenham develops a critique of medicine that uses hypothesis and philosophical principles that have not passed through the filter evaluator of experience.

Inspired by Francis Bacon, ${ }^{3}$ Sydenham aims to reduce all diseases to a few and "certain species", which he will call especie morbosae. According to Sydenham, most of the orderings of the diseases carried out up to that moment were based on hypotheses that did not correspond to the nature of the diseases but to the ingenuity and philosophical theories of their author.

More than this - it generally happens that even where we find a specific distribution, it has been done in subservience to some favorite hypothesis which lies at the bottom of the true phenomena; so that the distinction has been adapted not to the nature of the complaint, but to the views of the author and the character of his philosophy. ${ }^{4}$

The hypotheses, those purely speculative assumptions without any empirical foundation, are object of his criticism. These are postulates accepted a priori, which lack any proof or empirical verification. This is the main reason, says Sydenham, that a disease has often been confused with another, so that "the Materia Medica has grown so much and produced so little". ${ }^{5}$

In absence of a better rational guide, Sydenham proposes a return to Hippocrates, to the empirical roots of medicine. One return founded on

$2 \quad$ I will use the English translation of 1848.

3 "Preface to the third edition", Sydenham, 1848, Vol. I, 12; Yost, 1950, 84.

4 Sydenham, 1848, Vol. I, 13.

5 Ibid. 
the correct interpretation of the signs by means of a sensible perception,

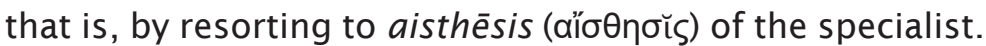

His proposal to correct the speculative drift of medicine has two fundamental principles: 1. Create a history or description of all diseases as graphic and natural as possible; 2 . Develop a stable healing practice or method related to that story. ${ }^{6}$

The history of the diseases proposed by Sydenham should be a detailed and exhaustive description, according to the inductive method defined by Bacon. ${ }^{7}$ The model for this history is the natural stories that botanists like John Ray do. ${ }^{8}$ To develop this story the researcher must be meticulous, attending to details that a layman would never take into account. ${ }^{9}$ Only an exhaustive record of the evident and natural phenomena of the disease will achieve this purpose.

To establish and develop the history of a disease is convenient to completely dispense that any philosophical hypothesis that may affect the intelligence of the researcher.

In writing the history of a disease, every philosophical hypothesis whatsoever, that has previously occupied the mind of the author, should lie in abeyance. This being done, the clear and natural phenomena of the disease should be noted -these, and these only. They should be noted accurately, and in all their minuteness. ${ }^{10}$

6 Sydenham, 1848, Vol. I, 12.

7 Medicine, however, did not require any external model, since from its origins it made use of the so-called "medical records", which are the best example of what Sydenham intended to develop. The reference to Bacon has no other purpose than to put medicine on the path of the Scientific Revolution, launched at the end of the 16th century.

8 "In the first place, it is necessary that all diseases be reduced to definite and certain species, and that, with the same care which we see exhibited by botanist in their phytologies; since it happens, at present, that many diseases, although included in the same genus, mentioned with a common nomenclature, and resembling one another in several symptoms, are, notwithstanding, different in their natures, and require a different medical treatment". Sydenham, 1848, Vol. I, 13.

9 "In respect to the histories of a disease, any one who looks at the case carefully, will see at once that an author must direct his attention to many more points than are usually thought of". Sydenham, 1848, Vol. I, 13.

10 Sydenham, 1848, Vol. I, 14. 
The reason for this prescription is that whoever follows a philosophical hypothesis (iatromechanical or iatrochemical), will only take into account the signs that coincide with said hypothesis, however insignificant they may be. While disregarding everything that does not match their assumptions.

Against such hypotheses, Sydenham establishes the principles for an ontological definition of the disease, as an observable, regular and autonomous entity. "The "peculiar and constant phenomena" pertaining to each disease, must be presented in the description of the disease, separately of the accidental and adventitious of each subject. ${ }^{12}$ Sydenham aims to separate the signs of illness, from the peculiarities of each sick subject. According to his clinical opinion, the symptoms vary, not only according to the patient's temperament and age, but also according to the prescribed curative method for his treatment. Symptoms are interpretable signs that change according to the medical approach.

...it is necessary, in describing any disease, to enumerate the peculiar and constant phenomena apart from the accidental and adventitious ones: these last-named being those that arise from the age or temperament of the patient, and from the different forms of medical treatment. It often happens that the character of the complaint varies with the nature of the remedies, and that symptoms may be referred less to the disease than to the doctor. Hence two patients with the same ailment, but under different treatment, may suffer from different symptoms. ${ }^{13}$

Against the refined and useless discussions that abound in the medical books of the time, calculus is the main practical instrument in the elaboration of a successful history of diseases. ${ }^{14}$ Unlike of the scholastic-aristotelic science, interested in the purely qualitative, the modern

11 "The ontological conception is concerned with disease causing entities, while the physiological conception involves deviation from functional norms". Marcum, 2008, 65 .

12 Sydenham, 1848, Vol. I, 14.

13 Ibid.

14 Sydenham, 1848, Vol. I, 15. 
seventeenth-century science give primary importance of the quantifiable, that is, of everything that could be perceived and ordered according to its smell, taste, texture, etc.

For Sydenham, the only way to determine morbid causes and define the cure is the safe and distinct perception of particular symptoms. Despite the variations, the behavior of nature is always the same in the production of diseases, producing similar symptoms in the most diverse constitutions. Ultimately, the development of the natural history of diseases must be based on the regularity of nature.

Notwithstanding this, Nature, in the production of disease, is uniform and consistent; so much so, that for the same disease in different persons the symptoms are for the most part the same... ${ }^{15}$

According to Sydenham, medicine has not been able to elaborate a true history of diseases because the disease was considered as a confusing and disorderly product of nature. ${ }^{16}$

With his ontological conception of disease, Sydenham introduces a different idea of human nature into medicine. Until the seventeenth century, health was considered a natural property of living beings. The disease, instead, which was understood rather as deprivation of health, i.e., like some out of nature or preternatural. With Sydenham, disease is no longer a preternatural disposition, a passive condition, but an active process, "an effort of nature," belonging entirely to human nature. ${ }^{17}$

In Sydenham's opinion, the disease is a set of observable and regular symptoms with predictable development. However, in a clearly Aristotelian position, rare cases, anomalies, should not be part of the history of diseases. ${ }^{18}$

\footnotetext{
15 Ibid.

16 Sydenham, 1848, Vol. I, 16.

17 Gracia, 1987, 272-273.

18 "Outlying forms of disease, and cases of exceeding rarity, I take no notice of. They do not properly belong to the histories of disease. No botanist takes the bites of a caterpillar as a characteristic of a leaf of sage". Sydenham, 1848, Vol. I, 14.
} 
On the other hand, Sydenham continued to be part of the humoralist tradition. He believed that the disease was the result of an imbalance, that is, the predominance of one of the humours over the others, by to weather variations or contagion. The humours will be expressed, therefore, through different substantial forms (eidos, हiٓठos) or species, producing the corresponding disorders:

From any one of these causes, or from any cause akin to them, the said humours become exalted into a substantial form or species; and these substantial forms or species manifest themselves in disorders coincident with their respective essences. ${ }^{19}$

Nevertheless, unlike plant and animal species, disease species do not self-sufficient but depend on the humours that engender them. ${ }^{20}$

On the other hand, Sydenham believes that the question about how can be cured the diseases should not be left unanswered, although the cause of most it is unknown. ${ }^{21}$ Investigating hidden or remote causes constitute an abuse of our abilities and a violation of nature, thus the healing should be the main objective of medicine.

It is useless that doctors try to discover the causes that the senses are not able to recognize. To heal successfully it is enough to know where is the immediate origin of the disease, as well as to distinguish precisely its symptoms, similarities and differences with other illness. ${ }^{22}$

Sydenham, like Galileo in physics, intends to replace the study of hidden and remote causes with the study of the nearest causes. ${ }^{23}$

\section{The Greek Roots of Sydenham Empiricism}

The Sydenham's preface to the Observationses medicae (1676) possesses important references to the controversy that took place between

\footnotetext{
19 Sydenham, 1848, Vol. I, 19.

20 Sydenham, 1848, Vol. I, 20.

21 Ibid.

22 Ibid.

23 Gracia, 1987, 274.
} 
medicine and philosophy at the origin of Hippocratic medicine, exposed in VM. It is likely, as Temkin thinks, that the appearance of modern empiricism has given philosophical value to treaties such as VM, which for themselves they would not have had. That is, only our present interest in empiricism leads us to attribute for anachronistic way an empiricist character to these works. Be that as it may, this would not be the only case of such reading. The interpretation we make of the past is always depend of our present interests and only since the present can we determine the antecedent character that a work or period may have had.

In any case, Sydenham's call for a return to the Hippocratic origins seems like a recursive reading of this kind. The incipient empiricism Hippocratic receives importance from the view of the clinical empiricism of the XVII, with its demand to reformulate the fundamentals of medicine and its method. In spite of the important transformations that were taking place in the medical field, the medicine in Sydenham's eyes was imprecise with respect to the empirical sciences of his time.

Similarly, at the end of the 5 th century B.C. the medicine fight by become independent from the presocratic philosophy of the nature, presenting itself as an autonomous discipline, with its own conception of nature

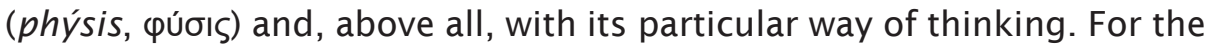
author of $V M$, only through medicine and not philosophical hypotheses (hypothéseis, úmó $\theta \varepsilon \sigma ı)$ is possible to win a true knowledge about what is the nature of man. Such hypotheses, as Sydenham believe, belong more to the author or to the art of writing than with medicine:

But I hold that whatever has been said or written about nature by a sophist or doctor pertains less to the art of medicine than to the art of writing, and also that it is impossible to have any clear knowledge about nature from other source than medicine. ${ }^{24}$

It is true that many of the main Hippocratic doctrines, such as the concept of health and the humoral theory, were medical transpositions of

24 Hippocrates, 2005, VM 20.2, $103=20$ I 10622 L. I will use the translation of Schiefsky. 
theories formulated by philosophers of nature such as Empédocles, Anaxagoras, Heraclitus, Tales, etc. Be that as it may, the philosophy of nature allowed medicine to get rid of the magical and theological thought that saturated its ancient clinical practice.

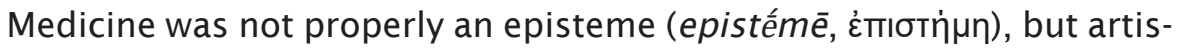

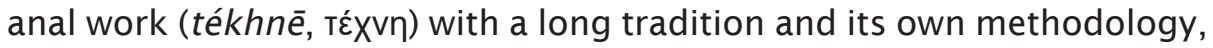
which gave it an important role in the Greek Paideia. Medical knowledge

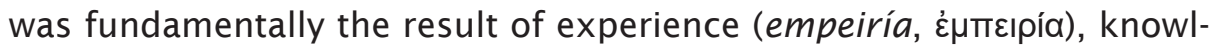
edge of the particular, not of the universal such as the episteme. Although medicine possessed its own forms of reasoning, in its origins it was not a theoretical and deductive system.

The author of VM defends, however, this knowledge against the unverifiable speculations of the philosophers. Hypotheses, he says, are only useful when dealing with invisible and enigmatic issues, such as things that are in heaven or under the earth. But they are not useful to talk about an art that already exists and that has its own form of knowledge on verifiable matters:

For this reason I have deemed that medicine has no need of a newfangled hypothesis, as do obscure and dubious matters. Concerning these things it is necessary to make use of a hypothesis if one undertakes to say anything at all about them -for example, about things in the sky or under the earth. If anyone should recognize and state how these things are, it would be clear neither to the speaker himself nor to his listeners whether what he says is true or not, for there is nothing by referring to which one would necessarily attain clear knowledge. ${ }^{25}$

The specific hypothesis against which it is directed is the one that pretends to reduce the cause of diseases to the imprecise and abstract principle (arché, ápx门்) of cold and heat. The cause (aitia, aitía), conversely, it has its origin in something as concrete and observable as the human diet.

$\overline{25 \quad \text { Hippocrates, }} 2005, V M 1.3,75=1$ I $3572 \mathrm{~L}$. 
Medicine arises of the need to investigate why the right diet for the healthy man is not convenient for the sick. Everyone's health is reduced to the reactions to what they eat and what they drink. ${ }^{26}$ Instead of considering a general theory that explains everything globally, the author of $V M$ believes that the only way to advance in medicine and achieve some form of knowledge is to consider the particularity of each case.

For this I think is what it is necessary for a doctor to know about the nature and to make every effort to know, if he is going to do any of the things that he must: what the human being is in relation to foods and drinks, and what it is in relation to other practices, and what will be the effect of each thing on each individual. ${ }^{27}$

This causal investigation from the aetiology (aitiology, aiтı০oүía) inaugurates a scientific destination for medicine, which will only get its fruit centuries later. The idea of cause, like something that can be confirmed by experience, has a similar value to deduction in geometry or mathematics. ${ }^{28}$ Her scientific and empirical significance is that it rejects the inference of observable phenomena based on unobservable principles.

The study of the signs of the disease process, in relation to the natural surrounding conditions, implied a Hippocratic turn towards empiricism and the commitment to a particular method of knowledge. Mainly this method consisted in understanding of the signs as natural facts, which must be interpreted by other natural facts. ${ }^{29}$ The interpretation of the signs seeks to achieve in this way, a comprehensive knowledge, to obtain a correct diagnosis and prognosis of each disease.

For this reason the doctor's tasks are much more varied and require more precision. For one must aim at measure; but you will find no measure -nor number nor weight be-

\footnotetext{
26 Hippocrates, 2005, VM 3.1, $77=33576 \mathrm{~L}$.

27 Hippocrates, 2005, VM 20.3, $103=20$ I 15622 L.

28 Eggers Lan's introduction to Hipócrates, 1991.

29 Guillaumin, 2005, 72.
} 
sides- by referring to which you will know with precision, except the feeling of the body. ${ }^{30}$

The exhaustive record of clinical history, such as the natural history of Sydenham diseases, constitutes the core idea of Corpus Hippocraticum. The detailed examination of each case is the basis of all medical treatment, which has the cure as its main objective, that is, to know what is appropriate in each case, the fair measure in all circumstances.

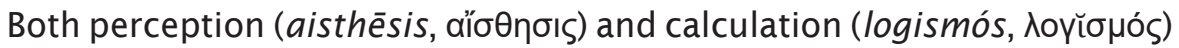
are indispensable in the process of seeking and acquiring medical knowledge, specifically regarding to diseases whose causes are beyond observation. ${ }^{31}$ Possibility of deducing the invisible from the visible facts, through the correct interpretation of the signs, made the analogy in a precious instrument of knowledge for medicine. ${ }^{32}$

To addressing the treatment of complex or unknown diseases, the method used was that of analogy. His goal was extract apparent similarities with known cases. The medicine, as Sydenham would say, should to apply a remedy that would have been effective in other similar cases. The more similarity there was, the greater the confidence in having reached a solution.

As Sydenham would recognize centuries later, the medical science should consist primarily in compiling effective treatments in known diseases, without trying to achieve any kind of abstract theoretical knowledge. Ultimately, the useful thing is not to know what causes the disease, but what suppresses it.

The primitive epistemological conditions of the medical task, forced to infer from the perceptible signs, those elements that cannot be perceived and that could be the cause of the disease. The search for similarities with other cases was the only method of reasoning that allowed to conclude from the obvious what couldn't be perceived.

30 Hippocrates, 2005, VM 9.3, 85 = 9 I 5-10 590 L.

31 "But one must learn these things from evident things outside the body". Hippocrates, 2005, VM 22.3, $105=22$ I $3626 \mathrm{~L}$.

32 Allen, 2001, 10-11; Lloyd, 1992, 254-255. 
The statement according to which "For what eluded the sight of the eyes is captures by signs of the mind", ${ }^{33}$ briefly expresses the Hippocratic medical knowledge procedure. Such inferential relationships established between the manifest and the hidden, the visible and the invisible, express the basic idea of inference through signs. ${ }^{34}$

Before the Aristotelian deductive method was imposed, as a model of reasoning to be followed by science, medicine had already produced one method of probabilistic and inductive inference adapted to its difficult conditions of knowledge. ${ }^{35}$

\section{The Simple Historical Method and Analogy}

The most influential Sydenham principles in Locke were the rejection of the search for knowledge from hypotheses and the "simple historical method" 36 implementation. This method, defined by Locke, similar to the Sydenham's natural history of diseases, ${ }^{37}$ understands the formation of knowledge from the exhaustive description of the facts.

Such two principles of Sydenham's clinical empiricism led Locke to generalize the study of signs to all science, eluding the investigation of the ultimate or hidden causes. According to Locke, knowledge must be a description of signs, not the investigation of the essences or substances of any kind.

If Sydenham set out to redefine medicine by writing a natural history of the disease, Locke wanted to cure the philosophy of speculative disease with the simple historical method. This method, like that of Sydenham, seeks its inspiration in the empirical disciplines of its time and in

\footnotetext{
33 Hippocrates, 2012, Art 11 2, p. $62=$ VI, 11, p. 21. L.

34 "And the basic idea of sign-inference can also be conveyed without any special reference to 'signs' or 'tokens'. Aristotle remarks that it is necessary to use visible things as witnesses for the invisible (EN 2. 2, 1104a13-14; cf. EE 1. 6, 1216 26 -8). The authors of the Hippocratic corpus speak often of the need to learn or investigate what is hidden from or on the basis of what is manifest (Vict. 1. 11-12; cf. VM 22). But perhaps the most suggestive statement of the principle is Anaxagoras' dictum: 'the phenomena are the vision of the non-evident' (S.E. M. 7. 140=B 21 a DK)". Allen, 2001, 2.
}

35 Guillaumin, 2005, 32-33.

36 Locke, 2015, B. I, cap. I, n. 2.

37 Anstey, 2002, 86-88. 
the so-called clinical records (clinical cases), which medicine had been using since the time of Hippocrates. Locke considers the simple historical method "a way of recording facts that is merely observational, descriptive, intersubjective and non-interpretive". ${ }^{38}$

For the dominant Aristotelian thought until that moment, science was not concerned with particulars or individuals, but with universals. For this reason, the medical clinic, as a particular knowledge, could not be considered part of science. Thus, medical science taught only physiological universals, leaving practical learning outside of university studies. Thanks to authors such as Sydenham, who began to study the disease like especie morbosae and to give a new epistemological value to the clinical scheme, the clinic could be part of scientific medicine. This required a substantial change in the idea of science. ${ }^{39}$

Locke rejects the idea of science conceived according to the Aristotelian deductive model. ${ }^{40}$ Like Sydenham, he rejects the claim of knowing on the basis of hypotheses or assumptions accepted a priori. ${ }^{41}$ He considers incompatible with scientific practice and knowledge of empirical reality, the absolute certainty search or necessary truths. Against the scholastic model of knowledge, Locke rejects the innate ideas existence and first principles a priori.

However, Locke acknowledges that a comprehensive descriptive program offers difficulties that are hard solve. One of the most important problems is that everything that cannot be observed will necessarily escape the margins of science. Like Procusto's bed, if the conditions proposed by empiricism are so restrictive, neither medicine nor many other sciences could have completely fit into their program, without suffering serious cuts. Given the narrows limits of perception and knowledge, something more than a purely deductive or purely descriptive certainty is necessary to do science:

\footnotetext{
38 Sánchez González, 2014, 5.

39 Gracia, 1987, 270-271.

40 "Folly to expect demonstration in everything". Locke, 2015, B. IV, cap. XI, n. 10

41 Locke, 2015, B. IV, cap. XII, n. 1
} 
Our knowledge being short, we want something else. The understanding faculties being given to man, not barely for speculation, but also for the conduct of his life, man would be at a great loss if he had nothing to direct him but what has the certainty of true knowledge. ${ }^{42}$

The incapacity to know everything with absolute certainty and the need to reach some kind of judgment, ${ }^{43}$ leads Locke to propose an intermediate path following the probability. Considering the uncertainty and the absence of clear demonstration, only probability makes it possible to progress in the path of knowledge:

Probability is the appearance of agreement upon fallible proofs. As demonstration is the showing the agreement or disagreement of two ideas by the intervention of one or more proofs, which have a constant, immutable, and visible connection one with another; so probability is nothing but the appearance of such an agreement or disagreement by the intervention of proofs, whose connection is not constant and immutable, or at least is not perceived to be so, but is, or appears for the most part to be so, and is enough to induce the mind to judge the proposition to be true or false, rather than the contrary. ${ }^{44}$

The probability complements the lack of knowledge, when the conditions to know are very limited; a circumstance that medicine regularly faces. The experience itself and the testimony of the experience of others are the two foundations of probable knowledge, so the coincidence of both forms of experiences allows achieving a security close to knowledge. ${ }^{45}$

Locke's defence of corpuscularism and his acceptance of the use of analogy as the basis of probability are recognition of the inability to fully

\footnotetext{
42 Locke, 2015, B. IV, cap. XIV, n. 1

43 Locke, 2015, B. IV, cap. XIV, n. 3

44 Locke, 2015, B. IV, cap. XV, n. 1

45 Locke, 2015, B. IV, cap. XVI, n. 6.
} 
comply with Sydenham's empiricism. In view of the inability to achieve direct perception, the analogy is the "great rule" of probable knowledge:

Analogy in these matters is the only help we have, and it is from that alone we draw all our grounds of probability. ${ }^{46}$

As we have pointed out, the reasoning by analogy was the best, if not the only, resource used by Hippocratic medicine in the interpretation of signs and in the diagnosis of diseases, especially those whose causes referred to processes internal of the organism. The theoretical and practical impossibility of making observations, to determine the causes in the case of internal diseases, as well as the urgency of establishing a curative treatment, force to search similarities in the accessible at first sight or what is already known. ${ }^{47}$ Sydenham recognizes him when he says:

Just as the outer man is built up as a framework of parts visible to the outward sense; so, also, is it the inner man similarly constituted of parts, however, consisting in the due and proper arrangements of the spirits, an arrangement cognizable only to the eye of reason. ${ }^{48}$

However, despite accepting the existence of causality at the microscopic level of the disease, Sydenham excluded from his project all pathological signs that were not visible to the naked eye. Faithful to his motto of fighting vain speculation, he was convinced that when we face imperceptible morbid states, "there is a strong tendency to indulge in idle, useless classification games". ${ }^{49}$

Sydenham considers it impossible to speculate on the alterations that take place in the blood and in the humours, without losing sight of the only guide we have: Nature. Following our speculations and assumptions we can have as many species of diseases as we can imagine. We take this

\footnotetext{
46 Locke, 2015, B. IV, cap. XVI, n. 12.

47 García Ballester, 1981, 221-222.

48 Sydenham, 1848, Vol. II, 91.

49 Yost, 1950, 90.
} 
way, a license that we would deny to any botanist, to whom we always demand evidence that can be confirmed by the senses. ${ }^{50}$

According to Laudan, doctors and astronomers like "Galen, Hippocrates and Ptolemy" had already insisted in that "a deductive science of first principles would not work". But only until the seventeenth century, it was possible to "redefine the most basic epistemic ambitions of knowledge scientific". ${ }^{51}$ The help of Sydenham's medical thought was invaluable in achieving a fundamentally empirical and experimental conception of science.

\section{Bibliographic References}

Allen, J., 2001, Inference from signs. Ancient debates about the nature of evidence. Oxford, University Press.

Anstey, P.R., 2002, Locke, Bacon and natural history. In: Early Science and Medicine, Vol. 7, No. 1, 65-92.

Estébanez García, F., 1998, Étimos griegos. Monemas básicos de léxico científico. Barcelona, Ediciones Octaedro.

Frede, M., 1988, The Empiricist Attitude towards Reason and Theory. Apeiron, Volume 21 , Issue 2, 79-98, ISSN (Online) 21 56-7093, ISSN (Print) 0003-6390, DOI: https://doi.org/10.1515/APEIRON.1988.21.2.79.

García Ballester, L., 1981, Experiencia y especulación en el diagnóstico galénico. Dynamis. Acta Hispanica ad Medicinae Scientiarumque Historiam Illustrandam, Vol. 1, 203-223.

Gracia, D., 1987, El nacimiento de la clínica y el nuevo orden de la relación médico enfermo. Cuadernos Hispanoamericanos (446-447), 69-282.

Guillaumin, G., 2005, El surgimiento de la noción de evidencia. Un estudio de epistemología histórica sobre la idea de evidencia científica. Universidad Nacional Autónoma de México, México.

50 Sydenham, 1848, Vol. I, 40.

51 Laudan, 2001, 87-88. 
Hippocrates, 1931, Nature of Man. Regimen in Health. Humours. Aphorisms. Regimen 1-3. Dreams. Translated by W.H.S. Jones. Loeb Classical Library 150. Cambridge, MA: Harvard University Press.

Hipócrates, 1991, De la medicina antigua. Introducción, texto crítico, traducción y notas de Conrado Eggers Lan. Universidad Autónoma de México, México.

Hippocrates, 2005, On Ancient Medicine. Translated with introduction and commentary by Mark J. Schiefsky, Studies in Ancient Medicine, Vol. 28, Leiden and Boston, Brill.

Hippocrates, 2012, On the Art of Medicine. Translated by Joel E. Mann, Studies in Ancient Medicine, Vol. 39, Leiden and Boston, Brill.

Laudan, L., 2001, El desarrollo y la resolución de las crisis epistemológicas: Estudios de caso en la ciencia y el derecho durante el siglo XVII. Signos filosóficos, núm. 5, enero-junio, 83-119.

Locke, J., 2000, An essay concerning human understanding. London; New York: Routledge.

Locke, J., 2015, An essay concerning human understanding. Australia: University of Adelaide Library. https://ebooks.adelaide.edu.au/l/locke/ john/l81 u/ index.html.

Lloyd, G.E.R., 1992, Polarity and Analogy: Two Types of Argumentation in Early Greek Thought (1966), Bristol: Bristol Classical Press; Indianapolis, IN: Hackett Publishing Co.

Marcum, J.A., 2008, An Introductory Philosophy of Medicine: Humanizing Modern Medicine. Springer Netherlands.

Rodríguez Sánchez, R.A., 2008, La evolución de la concepción de enfermedad en John Locke: el galenismo y la iatroquímica. ThéMata. Revista de Filosofía, núm. 40, 97-115.

Sánchez González, M.A., 2014, El ensayo Ars medica de John Locke, y la influencia de sus ideas médicas sobre la filosofía empirista. Asclepio, Revista de Historia de la Medicina y de la Ciencia, 66 (1), enero-junio 2014.

Sydenham, T., 1848, The Works of Thomas Sydenham, M.D. Translated from the Latin edition of Dr. Greenhill with A life of the author by 
R.G. Latham, M.D. Two volumes. London, Printed for the Sydenham Society.

Walmsley, J., 2008, Sydenham and the development of Locke's natural philosophy. In: British Journal for the History of Philosophy, 16(1), 65-83.

Yost, R.M., 1950, Sydenham's philosophy of science. Osiris, Vol. 9, 84-105. 